\title{
Measuring performance in the Portuguese banking industry with a Fourier regression model
}

\author{
Carlos Pestana Barros and Maria Rosa Borges* \\ UECE (Research Unit on Complexity and Economics), ISEG (School of \\ Economics and Management), Technical University of Lisbon, Rua Miguel \\ Lupi, 20, Lisbon, 1249-078, Portugal
}

This article analyses the determinants of banks' profitability in the Portuguese banking sector during the period 1990 to 2005. The study extends the established literature on modelling the banks' performance by applying a Fourier approximation in order to detect for possible nonlinearities between the profitability variables and the explanatory variables. In so doing, we verify that the introduction of the Fourier coefficients in the analysis quite improved the quality of the adjustments, the need to accept the existence of nonlinear relationships among the variables involved in the study thus becoming evident. The results of this article suggest that the best performing banks in the Portuguese banking sector are those which have endeavoured to improve their capital and labour productivity, those which have maintained a high dimension and, finally, those which have been able to reinforce their capital structure.

\section{Introduction}

The European banking sector at national level is presently confronted with several threats to their traditional profitability, including globalization, competition and the volatile market dynamics (Barros et al., 2007). The question of the determinants of bank performance is, in this context, an important issue. In this article we analyse the profitability of the Portuguese banking sector with a Fourier coefficient model to shed light on the determinants of bank efficiency.

This article departs from the literature on Fourier models in banking, since it does not adopt a frontier model framework, as in Berger and Mester (1997) and Altunbas et al. (2001), but instead adopts the approach of Enders and Sandler (2001), estimating a panel data regression, without the decomposition of the error term. The Fourier model has already been applied by Das and Das (2007) and Huang and Wang
(2004). Research of national banking markets includes Agostino et al. (2005) and Shen (2005).

The article is organized as follows: in Section II, we provide a survey of the bank-efficiency literature; in Section III, the methodology is described; in Section IV, the data are presented; in Section V, we set out the results; and finally, in Section VI, we present the conclusions.

\section{Literature Survey}

There is a growing body of empirical studies devoted to analyse bank performance. The first tradition of studies analysed bank performance with frontier models. For a review of the recent literature related to frontier models, the reader is referred to the survey of Berger and Humphrey (1997), which summarizes all the work done in this area until 1997 and presents a survey on this topic. The second tradition of studies,

*Corresponding author. E-mail: mrborges@iseg.utl.pt 
which is relevant to this article, analyses the link between market structure and bank performance according the structure-conduct-performance (SCP) hypothesis (Gilbert, 1984).

According to the SCP hypothesis, market concentration fosters collusion among banks thus exerting a direct influence on competition. The validation of this hypothesis is supported when the market concentration exerts a positive influence on bank performance, regardless of the degree of efficiency of the firm. Early studies, which accepted this hypothesis, including Haggestad and Mingo (1977), Spellman (1981) and Rhoades (1982), have been criticized by Gilbert (1984). An alternative hypothesis has been advanced to explain bank performance, namely, the efficient hypothesis, which maintains that an industry's structure arises as a result of superior operating efficiency by a particular bank. Gilbert (1984) notes that out of 44 studies listed in a literature survey, 32 support the SCP hypothesis. The efficiency hypothesis is supported by Smirlock (1985) and Evanoff and Fortier (1988). In Europe, Molyneux and Forbes (1995) support the SCP hypothesis, but Maudos (2001) rejects the SCP for the Spanish banking market.

Econometric Fourier models have been applied in banking in a somewhat different context, namely in the context of frontier models, by Berger and Mester (1997) who found that it fits the bank data better than the commonly specified local translog function. Berger and Mester (2003) analysed technological change, deregulation and changes in competition in banking with a Fourier cost function. Altunbas et al. (2001) analysed the efficiency on European banking with a Fourier model. This article departs from this research, not adopting a frontier model, but rather adopting a Fourier panel data regression without decomposition of the errors terms, alongside the approach chosen by Enders and Sandler (2001).

\section{Methodology}

In this empirical test, we attempt to explain banks' profitability with respect to a set of explanatory variables, all of them corresponding to endogenous factors under the control of banks' management. Explanatory variables of productivity, size, capitalization and portfolio composition of the banks are employed. The relationship we wish to estimate can therefore be represented by the following generic equation:

Profitability $_{t}=f\left(\right.$ Prodl $_{t}$, Prodc $_{t}$, Size $_{t}$, Solv $_{t}$, Base $\left._{t}\right)$

\footnotetext{
${ }^{1}$ For more details on this methodology see Becker et al. (2002).
}

where Prodl is labour productivity, Prodc is capital productivity, Size is the size variable (a proxy for market share), Solv is bank capitalization and Base is the bank portfolio composition. The main contribution of this study relatively to the established literature on modelling banks' profitability resides in its attempt to detect the existence of nonlinear relationships among the involved variables, which is accomplished through a Fourier approximation.

Fourier approximations have been used in other types of studies on banking sector. Examples of these are Altunbas et al. (2001), Mitchell and Onvural (1996) and Berger et al. (1997), who use the Fourier flexible functional form to examine the specification of the cost structure in the banking sector. These studies have stated that the Fourier flexible form is the global approximation, which can be shown to dominate the conventional translog form, normally used in that kind of study. The methodology used in these studies was first proposed by Gallant $(1981,1982)$.

An alternative way to capture any potential nonlinearities in the data with a Fourier approximation is to use the methodology of Ludlow and Enders (2000), as we choose to do in our study. As stated by Enders and Sandler (2001), the Fourier approximation suggested by Ludlow and Enders (2000) is something quite different from the standard spectral analysis, in which instead of simply using the most significant frequencies in order to approximate the time-varying coefficients associated with the explanatory variables, all possible integer frequencies are used in the interval $k=[1, T / 2]$, where $T$ corresponds to the number of observations.

We now expose the type of nonlinear methodology suggested by Ludlow and Enders (2000). Consider the simple model

$$
y_{t}=\alpha \cdot x_{t}+\varepsilon_{t}
$$

where $x_{t}$ is a stationary random variable and $\varepsilon_{t}$ is a white-noise disturbance such that $E_{t-1} \varepsilon_{t}=0$ and $E_{t-1} \varepsilon_{t}^{2}=\sigma^{2}$ for every time period $t$. A simple modification of Equation 3 is to allow the coefficient $\alpha$ to be a time-dependent function denoted by $\alpha(t)$, thus resulting in a model that is linear in variables, but nonlinear in parameters (i.e. with a time-varying coefficient), ${ }^{1}$

$$
y_{t}=\alpha(t) \cdot x_{t}+\varepsilon_{t}
$$

As referred by Ludlow and Enders (2000), although we allow the coefficient $\alpha(t)$ to be a deterministic, but unknown, function of time, if $\alpha(t)$ is an absolutely 
integrable function, for any desired level of accuracy, the behaviour of $\alpha(t)$ can be represented precisely by a sufficiently long Fourier series of the form:

$$
\alpha_{t}=A_{0}+\sum_{i=1}^{n}\left[A_{i} \sin \frac{2 \pi k_{i}}{T} \cdot t+B_{i} \cos \frac{2 \pi k_{i}}{T} \cdot t\right]
$$

where $k$ is an integer in the interval 1 to $T / 2$ and $n$ refers to the number of frequencies contained in the process generating $\alpha(t)$.

The key point in using Equation 4 is that the behaviour of any deterministic sequence can be readily captured by a sinusoidal function, even though the sequence in question is not periodic. As such, nonlinear coefficients can be represented by a deterministic time-dependent coefficient model without first specifying the nature of the asymmetric adjustments. The nature of the approximation is such that the standard linear model, Equation 2, emerges as a special case when all values of $A_{i}$ and $B_{i}$ in Equation 4 are equal to 0 . Thus, the specification problem of the model is transformed into one of selecting the proper frequencies to include in Equation 4.

In this article, we do this using the four-step procedure suggested by the authors (Ludlow and Enders, 2000, pp. 338-9), which is one possible strategy to identify the particular Fourier coefficients to include in the model. We also make use of the Enders-Ludlow critical values for the null hypothesis $A_{i}=0$ or/and $B_{i}=0\left(t^{*}\right.$ and $\left.F^{*}\right)$, which are the result of a Monte Carlo experiment to calculate the appropriate critical values for an AR(1) model. Although our regressors are not lagged dependent variables, the results obtained by Enders and Hoover (2003) suggest that the difference between the Enders-Ludlow critical values and the appropriate ones should not be very significant. Nevertheless, we will also make use of Schwarz Bayesian Criterion ( $S B C$ ) to select the appropriate frequencies and then to confirm whether the coefficients belong in the model. In so doing, we avoid the problem of a possible overfitting in the model.

Although in Ludlow and Enders (2000) Equation 2 is assumed to be a simple linear AR(1), this methodology can also be applied to a more general model, where the intercept term and the coefficients of all explanatory variables may fluctuate over time (Becker et al., 2002). Therefore, applying the methodology described here to our generic Equation 1 and restricting ourselves to only two possible frequencies for all the regressors and to four frequencies for the productivity regressors result in the following general model:
Profitability

$$
\begin{aligned}
= & \alpha_{0}+\alpha_{1} \text { Prodl }_{t}+\alpha_{2} \text { Prodc }_{t}+\alpha_{3} \text { Size }_{t}+\alpha_{4} \text { Solv }_{t}+\alpha_{5} \text { Base }_{5} \\
& +\sum_{i=1}^{2}\left[a_{0 i} \sin \left(2 \pi \cdot k_{0 i} \cdot \frac{t}{T}\right)+b_{0 i} \cos \left(2 \pi \cdot k_{0 i} \cdot \frac{t}{T}\right)\right] \\
& +\sum_{i=1}^{4}\left[a_{1 i} \sin \left(2 \pi \cdot k_{1 i} \cdot \frac{t}{T}\right)+b_{1 i} \cos \left(2 \pi \cdot k_{1 i} \cdot \frac{t}{T}\right)\right] \cdot \text { Prodl }_{t} \\
& +\sum_{i=1}^{4}\left[a_{2 i} \sin \left(2 \pi \cdot k_{2 i} \cdot \frac{t}{T}\right)+b_{2 i} \cos \left(2 \pi \cdot k_{2 i} \cdot \frac{t}{T}\right)\right] \cdot \text { Prodc }_{t} \\
& +\sum_{i=1}^{2}\left[a_{3 i} \sin \left(2 \pi \cdot k_{3 i} \cdot \frac{t}{T}\right)+b_{3 i} \cos \left(2 \pi \cdot k_{3 i} \cdot \frac{t}{T}\right)\right] \cdot \text { Size }_{t} \\
& +\sum_{i=1}^{2}\left[a_{4 i} \sin \left(2 \pi \cdot k_{4 i} \cdot \frac{t}{T}\right)+b_{4 i} \cos \left(2 \pi \cdot k_{4 i} \cdot \frac{t}{T}\right)\right] \cdot \text { Solv }_{t} \\
& +\sum_{i=1}^{2}\left[a_{5 i} \sin \left(2 \pi \cdot k_{5 i} \cdot \frac{t}{T}\right)+b_{5 i} \cos \left(2 \pi \cdot k_{5 i} \cdot \frac{t}{T}\right)\right] \cdot \text { Base }_{t}+\varepsilon_{t}
\end{aligned}
$$

The interpretation of Equation 5 is that the magnitude of any fluctuations in the constant term is captured by nonzero values of $a_{0 i}$ and $b_{0 i}$. Similarly, fluctuations in the coefficients of explanatory variables are captured by nonzero values of $a_{j i}$ and $b_{j i}$, where $j=1, \ldots, 5$. The frequencies of the fluctuations in the constant term are given by $k_{0 i}$, while the frequencies of the fluctuations in the coefficients of explanatory variables are given by $k_{j i}$, where $j=1, \ldots, 5$.

\section{Data}

This study uses a balanced-panel database on Portuguese banks from 1990 to 2005, including a total of 160 observations. The banks used in the study and their economic characteristics in 1990 and 2005 are presented in Tables 1 and 2, respectively. The sample includes the main national private banks (BCP and BES), the sole state-owned bank (CGD), the sole mutualist bank (MG) and the only foreign bank (Barclays), which were actively present in the market in all the years of the period under analysis. As can be seen in Table 1, at the beginning of the period analysed, the sample represents $58 \%$ of the total market share and $55.7 \%$ of all bank branches.

Table 2 shows that at the end of the period examined, the sample represents $70.1 \%$ of the total market share and $61.7 \%$ of the total bank branches. The net interest margins range from 1.35 to 1.92 , a value that resembles the average interest margin observed in the European market (Goddard et al., 2001, p. 12). The ratio of noninterest income to gross income ranges from 16.03 to $63.08 \%$, which contrasts with the European values in the median (Goddard et al., 2001, p. 13). The ratio of 
Table 1. Characteristics of the bank sample in 1990

\begin{tabular}{llllllr}
\hline Banks & $\begin{array}{l}\text { Market share } \\
(\%)\end{array}$ & $\begin{array}{l}\text { No of } \\
\text { branches }\end{array}$ & $\begin{array}{l}\text { Net interest } \\
\text { margins }\end{array}$ & $\begin{array}{l}\text { Non-interest income/gross } \\
\text { income }(\%)\end{array}$ & $\begin{array}{l}\text { Cost/income } \\
\text { ratio }(\%)\end{array}$ & $\begin{array}{l}\text { Return on } \\
\text { equity }(\%)\end{array}$ \\
\hline Banif & 1.4 & 26 & 1.76 & 11.11 & 87.25 & 12.88 \\
Barclays & 0.6 & 8 & 1.31 & 9.25 & 99.30 & 0.85 \\
BCP & 4.5 & 131 & 1.58 & 19.64 & 87.95 & 10.84 \\
BES & 8 & 163 & 1.65 & 14.23 & 92.05 & 28.56 \\
BIC & 1.1 & 6 & 1.49 & 13.48 & 91.71 & 10.81 \\
BNU & 4.7 & 150 & 1.48 & 25.18 & 99.24 & 1.99 \\
BTA & 1.9 & 172 & 1.69 & 13.91 & 91.43 & 20.76 \\
CGD & 5.5 & 414 & 1.57 & 8.51 & 97.99 & 11.97 \\
CPP & 27.6 & 75 & 1.38 & 16.62 & 93.01 & 8.88 \\
MG & 2.8 & 37 & 1.47 & 3.93 & - & 22.54 \\
Total $(\%)$ & 58 & 55.7 & - & - & - \\
\hline
\end{tabular}

Table 2. Characteristics of the bank sample in 2000

\begin{tabular}{llllllr}
\hline Banks & $\begin{array}{l}\text { Market share } \\
(\%)\end{array}$ & $\begin{array}{l}\text { No of } \\
\text { branches }\end{array}$ & $\begin{array}{l}\text { Net interest } \\
\text { margins }\end{array}$ & $\begin{array}{l}\text { Non-interest income/gross } \\
\text { income }(\%)\end{array}$ & $\begin{array}{l}\text { Cost/income } \\
\text { ratio }(\%)\end{array}$ & $\begin{array}{l}\text { Return on equity } \\
(\%)\end{array}$ \\
\hline Banif & 1.6 & 116 & 1.83 & 32.88 & 95.31 & 7.27 \\
Barclays & 0.05 & 52 & 1.61 & 40.38 & 94.32 & 13.04 \\
BCP & 20.7 & 1.221 & 1.70 & 40.92 & 90.19 & 38.44 \\
BES & 10.8 & 469 & 1.35 & 63.08 & 96.62 & 18.82 \\
BIC & 2.8 & 121 & 1.50 & 17.72 & 89.96 & 24.30 \\
BNU & 2.5 & 177 & 1.56 & 52.87 & 98.77 & $4.33^{\mathrm{a}}$ \\
BTA & 0.07 & 276 & 1.76 & 44.15 & 95.27 & $10.66^{\mathrm{b}}$ \\
CGD & 8.3 & 594 & 1.62 & 54.07 & 92.81 & 20.54 \\
CPP & 18.5 & 154 & 1.78 & 23.82 & 98.90 & $2.88^{\mathrm{b}}$ \\
MG & 3.8 & 259 & 1.92 & 16.03 & 89.86 & - \\
Total & 70.1 & 61.7 & - & - & - & 17.17 \\
\hline
\end{tabular}

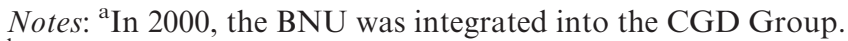

'This atypical values are due to BTA's and CPP's integration into the Santander Group.

cost to income is higher than the values observed in the European banking sector (Goddard et al., 2001, p. 15) while the return on equity is lower.

As mentioned above, the study is concerned with the relationship between the bank's profitability and its productivity, size, capitalization and portfolio composition. The Return on Assets ( $R O A)$ and the Return on Equity $(R O E)$ are used as profitability variables. The productivity variables are labour productivity (Prodl), measured as the ratio between net income and the number of employees, and capital productivity $(\operatorname{Prodc})$, measured as the ratio between net income and the number of branches. Three different size variables were used, the log of total assets (Sizea), the formula $-1 /$ (total deposits/1 000 000) (Sized) and the $\log$ of bank product (Sizepb). Bank capitalization, determined as the ratio of between own funds and total assets, and portfolio composition, determined as the ratio between total deposits and total assets, are represented by Solv and Base, respectively.
All data are in 1995 real terms, converted using the GDP deflator, with the exception of the number of agencies and the number of employees. Table 3 reports descriptive statistics of the variables used in the model, where the heterogeneity of the banks included in sample showed in Tables 1 and 2 can be confirmed.

\section{Results}

In accordance with the strategy of identification of the Fourier coefficients suggested in Ludlow and Enders (2000), we begin estimating the general model (Equation 5) without the inclusion of the Fourier coefficients, that is, assuming that the resulting coefficients would be invariable.

The first empirical results are revealed to be weak when $R O E$ is used as a profitability variable. Equally, of the three size variables used, only Sized is statistically significant. To save space, the results are only 
Table 3. Descriptive statistics of the variables used in the model (1990-2005)

\begin{tabular}{|c|c|c|c|c|}
\hline Variables & Mean & SD & Min. & Max. \\
\hline$R O A$ & 0.0064 & 0.0048 & -0.0166 & 0.0179 \\
\hline$R O E$ & 0.1349 & 0.1048 & -0.3521 & 0.5352 \\
\hline Prodl & 3.0454 & 2.4157 & -4.5241 & 12.8048 \\
\hline Prodc & 56.8958 & 53.9621 & -112.8874 & 358.6027 \\
\hline Sizea & 13.9296 & 1.1561 & 11.3567 & 16.1486 \\
\hline Sized & -2.0841 & 2.7260 & -15.7479 & -0.1124 \\
\hline Sizepb & 10.2772 & 1.0887 & 8.0775 & 12.5612 \\
\hline Solv & 0.0610 & 0.0292 & 0.0257 & 0.1635 \\
\hline Base & 0.8426 & 0.0935 & 0.5027 & 0.9543 \\
\hline
\end{tabular}

Notes: The variables have been deflated using GDP deflator with 1995 as a base year.

discussed for the model employing ROA and Sized as variables of profitability and size, respectively.

With regard to the estimation results without Fourier coefficients, we conclude that, based upon conventional $t$-ratios, the constant term (Constant) and the banks' portfolio composition (Base) are not statistically significant explanations for the changes in the banks' profitability. Therefore, these are excluded from the estimations. The model appears to fit well with an adjusted $R^{2}$ of $74.6 \%$ and an $F$-statistic that rejects the joint hypothesis that the coefficients on all variables are not significantly different from zero. ${ }^{2}$
These first results without Fourier coefficients confirm the a priori expectations that the bank performance $(R O A)$ is positively explained by the bank labour and capital productivity (Prodl and Prodc), the bank size (Sized) and the bank capitalization ratio (Solv).

Next, we test the existence of nonlinear relationships among the dependent variable $R O A$ and the explanatory variables used in the study. In other words, we proceed to identify the particular Fourier coefficients to include in our model. The specification problem of the model now consists in selecting the proper frequencies to include in the Fourier coefficients (when they exist

Table 4. Estimation results (dependent variable $R O A$ )

\begin{tabular}{|c|c|c|c|c|}
\hline Variables & Parameters & Coefficients & SE & $t$-Ratio \\
\hline Prodl & $\alpha_{1}$ & 0.0008083 & 0.0000898 & 9.00483 \\
\hline Prodc & $\alpha_{2}$ & 0.0000589 & 0.0000049 & 11.94012 \\
\hline Sized & $\alpha_{3}$ & 0.0002957 & 0.0000604 & 4.89554 \\
\hline Solv & $\alpha_{4}$ & 0.0187000 & 0.0046618 & 4.00407 \\
\hline $\operatorname{Sin}\left(w_{01}\right) *$ Constant & $a_{01}$ & -0.0011860 & 0.0001690 & -7.01778 \\
\hline $\operatorname{Cos}\left(w_{11}\right) *$ Prodl & $b_{11}$ & 0.0002117 & 0.0000454 & -4.66259 \\
\hline $\operatorname{Sin}\left(w_{12}\right) *$ Prodl & $a_{12}$ & 0.0002129 & 0.0000598 & -3.55755 \\
\hline $\operatorname{Cos}\left(w_{13}\right) *$ Prodl & $b_{13}$ & 0.0002573 & 0.0000431 & 5.97020 \\
\hline $\operatorname{Cos}\left(w_{14}\right)^{*}$ Prodl & $b_{14}$ & 0.0002056 & 0.0000461 & 4.45474 \\
\hline $\operatorname{Sin}\left(w_{21}\right) * \operatorname{Prod} c$ & $a_{21}$ & 0.0000108 & 0.0000024 & 4.43538 \\
\hline $\operatorname{Sin}\left(w_{22}\right) *$ Prodc & $a_{22}$ & -0.0000146 & 0.0000024 & -6.09532 \\
\hline $\operatorname{Cos}\left(w_{31}\right) *$ Sized & $b_{31}$ & -0.0004914 & 0.0000684 & -7.18558 \\
\hline $\operatorname{Cos}\left(w_{32}\right) *$ Sized & $b_{32}$ & 0.0002774 & 0.0000581 & 4.77379 \\
\hline $\operatorname{Sin}\left(w_{41}\right) *$ Solv & $a_{41}$ & -0.0104000 & 0.0027589 & -3.78107 \\
\hline $\operatorname{Sin}\left(w_{42}\right) *$ Solv & $a_{42}$ & -0.0085751 & 0.0027403 & -3.12925 \\
\hline $\operatorname{Cos}\left(w_{51}\right)^{*}$ Base & $b_{51}$ & -0.0005987 & 0.0001852 & -3.23210 \\
\hline $\operatorname{Sin}\left(w_{52}\right) *$ Base & $a_{52}$ & -0.0005755 & 0.0001904 & -3.02178 \\
\hline Observations & & 160 & & \\
\hline$F(4.93)^{\mathrm{a}}$ & & 1051.497 & & \\
\hline$F(17.93)$ & & 303.870 & & \\
\hline$R^{2}$-adjusted & & 0.943 & & \\
\hline$S B C$ & & -910.184 & & \\
\hline
\end{tabular}

Note: ${ }^{\text {a }}$ The $F$-statistic for the joint hypothesis that the coefficients $\alpha_{1}, \alpha_{3}, \alpha_{3}$ and $\alpha_{4}$ are equal to 0 .

\footnotetext{
${ }^{2}$ These results, as well as those for all the other models that use $R O E$ and the size variables Sizea and Sizepb, are available on request from the authors.
} 
and are statistically significant) associated with the various explanatory variables. Following the abovementioned four-step identification strategy, we obtain the results presented in Table 4.

As can be observed, the introduction of the Fourier coefficients into the model improves the quality of the adjustment, resulting in an adjusted $R^{2}$ of $94.3 \%$. This increase in the global significance of the model can also be verified by the $F$-statistic associated with the hypothesis of nullity of the invariable coefficients $\left(\alpha_{1}=\alpha_{2}=\alpha_{3}=\alpha_{4}=0\right)$, which increased four times (from 269.4 to 1051.5). The significance is further confirmed by the obtaining of a quite inferior value for $S B C$ (which decreased from -792.848 to -910.184 ). A representation of the residuals from the model with and without Fourier coefficients is shown in Fig. 1. The comparison confirms the values of $S B C$, which are quite favourable relative to the nonlinear model.

As mentioned earlier, the tests to the statistic significance of the Fourier coefficients should not be

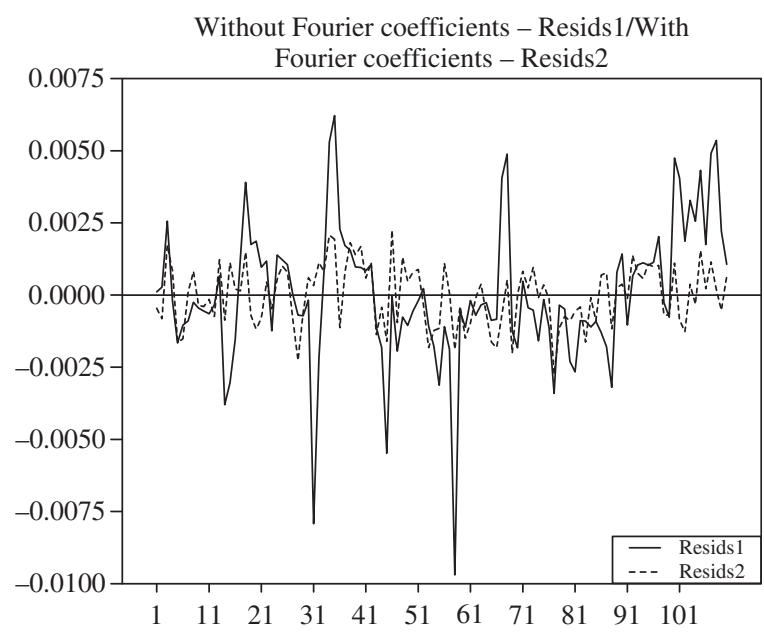

Fig. 1. Residuals of the estimation - model made with base in the standard critical values $t$ and $F$, but rather in the critical values $t^{*}$ and $F^{*}$ (not presented, are available on request from the authors). ${ }^{3}$ Additionally, we do not accept any coefficient whose inclusion does not result in a decrease of the $S B C$, which is a model selection criteria that trades off a reduction in the sum of squared residuals for a more parsimonious model and therefore avoids a possible problem of overfitting in the model. 13 Fourier coefficients were included in the model. The inclusion of Fourier coefficients is accepted even for the regressors that previously had not revealed statistically significant explanations for the alterations in the performance of the banks (Constant and Base), which means that both present an exclusively nonlinear relationship with the profitability variable $R O A$. The Fourier coefficients included in the model and the associated frequencies $k_{j i}$ are reported in Table 5 below.

As we can see, all the variables (with the exception of the constant term) have more than one single frequency associated. The variable Prodl has $k_{11}=14, k_{12}=5$, $k_{13}=2$ and $k_{14}=13$ associated with coefficients $b_{11}$, $a_{12}, b_{13}$ and $b_{14}$, respectively; Prodc has $k_{21}=10$ and $k_{22}=18$ associated with $a_{21}$ and $a_{22} ;$ Sized has $k_{31}=1$ and $k_{32}=8$ associated with $b_{31}$ and $b_{32}$; Solv has $k_{41}=8$ and $k_{42}=11$ associated with $a_{41}$ and $a_{42}$; and Base has $k_{51}=30$ and $k_{52}=16$ associated with $b_{51}$ and $a_{52}$. Using the $t^{*}$-test statistic, almost all the Fourier coefficients are significantly different from 0 at the $1 \%$ level. The exceptions are $a_{12}, a_{42}, b_{51}$ and $a_{52}$, which are only statistically significant at the $5 \%$ level.

An important aspect to point out is the behaviour of the coefficients of the model along the sample. As can be seen through the graphic representation of the estimated coefficients (Fig. 2), all the variables present a nonlinear relationship with profitability. Focusing our attention on the variables with a constant part in the associated coefficients, we can see that, although

Table 5. Fourier coefficients of the model

\begin{tabular}{|c|c|c|c|c|c|c|c|}
\hline & $a_{01}$ & $b_{11}$ & $a_{12}$ & $b_{13}$ & $b_{14}$ & $a_{21}$ & $a_{22}$ \\
\hline Coefficient & -0.001186 & -0.000212 & -0.000213 & 0.000257 & 0.000206 & 0.000011 & -0.000015 \\
\hline$t$-Ratio & -7.02 & -4.66 & -3.56 & 5.97 & 4.45 & -4.44 & -6.10 \\
\hline \multirow[t]{2}{*}{ Frequency $\left(k_{j i}\right)$} & $k_{01}=3$ & $k_{11}=14$ & $k_{12}=5$ & $k_{13}=2$ & $k_{14}=13$ & $k_{21}=10$ & $k_{22}=18$ \\
\hline & $b_{31}$ & $b_{32}$ & $a_{41}$ & \multicolumn{2}{|c|}{$a_{42}$} & $b_{51}$ & $a_{52}$ \\
\hline Coefficient & -0.000491 & 0.000277 & \multicolumn{2}{|l|}{-0.010400} & -0.008575 & -0.000599 & -0.000575 \\
\hline$t$-Ratio & -7.19 & 4.77 & \multicolumn{2}{|l|}{-3.78} & -3.13 & -3.23 & -3.02 \\
\hline Frequency $\left(k_{j i}\right)$ & $k_{31}=1$ & $k_{32}=8$ & \multicolumn{2}{|l|}{$k_{41}=8$} & $k_{42}=11$ & $k_{51}=30$ & $k_{52}=16$ \\
\hline
\end{tabular}

${ }^{3}$ Note that $F^{*}$ does not correspond to the critical value associated to the hypothesis of nullity of all the Fourier coefficients but instead to the critical value associated to the test of nullity of the pairs $\sin / \cos$ of the Fourier coefficients $\left(a_{j i}=b_{j i}=0\right)$. 

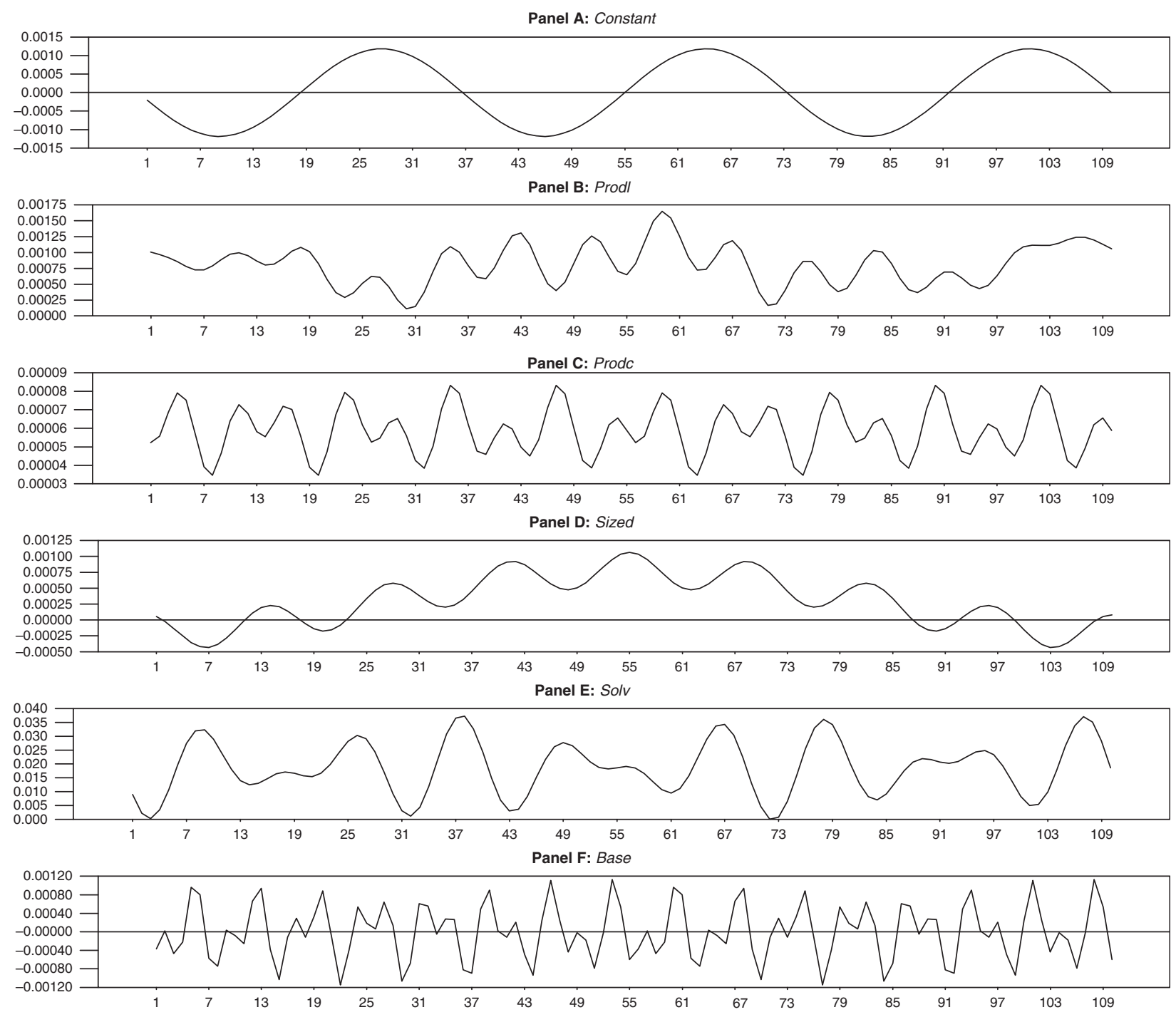

Fig. 2. Estimated coefficients of the model

the coefficients of Prodl, Prodc and Solv always continue to assume positive values along the sample, the variable Sized has a coefficient that assumes negative values in some parts of the sample. This continues to be in agreement with the remaining empirical evidence that, as mentioned in a synthesis by Naceur and Goaied (2001), has been supporting the existence of a positive or negative effect on the relationship between the bank's size and its profitability.

Another important aspect to mention is the consistency presented by the Fourier model. The fact that the introduction of the Fourier coefficients into the model in order to not cause a significant alteration in the estimated values of the coefficients $\alpha_{1}, \alpha_{2}, \alpha_{3}$ and $\alpha_{4}$ means that the model has a high degree of consistency.

With reference to the model (Table 4), one may then rank the statistically significant explanatory variables in terms of their contribution to explaining the banks' profitability according to the absolute values of their $t$-ratios. In so doing and taking into consideration that the relevant analysis concerns the coefficients associated with the explanatory variables that have a constant (invariable) part, one finds the following ranking (in decreasing order of importance) for the more important determinants: (1) capital productivity, (2) labour productivity, (3) bank size and (4) bank capitalization.

\section{Conclusion}

The main objective of this study is to analyse the determinants of banks' profitability in the Portuguese banking sector during the period 1990 to 2005. This article extends the established literature on modelling the 
banks' profitability by applying Fourier coefficients to detect for possible nonlinearities between the performance variables and the explanatory variables. In so doing, we verify that the introduction of the Fourier coefficients in the analysis quite improved the quality of the adjustments, the need to accept the existence of nonlinear relationships among the variables involved in the study thus becoming evident.

The findings of this article therefore suggest that the best performing banks in the Portuguese banking sector are those which have endeavoured to improve their capital and labour productivity, those which have maintained a high dimension and, finally, those which have been able to reinforce their capital structure. Despite not having a variable for market concentration, the statistical significance of market share suggests that the SCP is supported, validating Molyneux and Forbes (1995).

\section{References}

Agostino, M., Leonida, L. and Trivieri, F. (2005) Profits persistence and ownership: evidence from the Italian banking sector, Applied Economics, 37, 1615-21.

Altunbas, Y., Gardener, E., Molyneux, P. and Moore, B. (2001) Efficiency in European banking, European Economic Review, 45, 1931-55.

Barros, C., Ferreira, C. and Williams, J. (2007) Analysing the determinants of performance of the best and worst European banks: a mixed logit approach, Journal of Banking and Finance, 31, 2189-203.

Becker, R., Enders, W. and Hurn, A. (2002) A general test for time-dependence in parameters, Journal of Applied Econometrics, 19, 899-906.

Berger, A. and Humphrey, D. (1997) Efficiency of financial institutions: international survey and directions for future research, European Journal of Operational Research, 98, 175-212.

Berger, A., Leusner, J. and Mingo, J. (1997) The efficiency of bank branches, Journal of Monetary Economics, 40, 141-62.

Berger, A. and Mester, L. (1997) Inside the black box: what explains differences in the efficiency of financial institutions, Journal of Banking and Finance, 21, 895-947.

Berger, A. and Mester, L. (2003) Explaining the dramatic changes in performance of US banks: technological change, deregulation, and dynamic changes in competition, Journal of Financial Intermediation, 12, 57-95.

Das, A. and Das, S. (2007) Scale economies, cost complementarities and technical progress in Indian banking: evidence from Fourier flexible functional form, Applied Economics, 39, 565-80.
Enders, W. and Hoover, G. (2003) The effect of robust growth on poverty: a non-linear analysis, Applied Economics, 35, 1063-71.

Enders, W. and Sandler, T. (2001) Non-linear effects and improved estimates of transnational terrorism, Unpublished Paper.

Evanoff, D. and Fortier, D. (1988) Reevaluation of the structure-conduct-performance paradigm in banking, Journal of Financial Service Research, 1, 249-60.

Gallant, A. (1981) On the bias in flexible functional forms and essentially unbiased form: the Fourier flexible form, Journal of Econometrics, 46, 229-45.

Gallant, A. (1982) Unbiased determination of production technologies, Journal of Econometrics, 20, 285-324.

Gilbert, R. (1984) Bank market structure and competition, Journal of Money, Credit and Banking, 16, 617-45.

Goddard, J., Molyneux, P. and Wilson, J. (2001) European Banking: Efficiency, Technology and Growth, John Wiley and Sons, New York.

Haggestad, A. and Mingo, J. (1977) The competition condition of US banking markets and the impact of structural reforms, Journal of Finance, 32, 649-61.

Huang, T. and Wang, M. (2004) Estimation of scale and scope economies in multiproduct banking: evidence from the Fourier flexible functional form with panel data, Applied Economics, 36, 1245-53.

Ludlow, J. and Enders, W. (2000) Estimating non-linear ARMA models using Fourier coefficients, International Journal of Forecasting, 16, 333-47.

Maudos, J. (2001) Rendabilidad, Estructura de Mercado y Efficiencia en la Banca, Revista de Economia Aplicada, 25, 193-207.

Mitchell, K. and Onvural, N. (1996) Economies of scale and scope at large commercial banks: evidence from the Fourier flexible functional form, Journal of Money, Credit and Banking, 28, 178-99.

Molyneux, P. and Forbes, W. (1995) Market structure and performance in European banking, Applied Economics, 27, 155-9.

Naceur, S. and Goaied, M. (2001) The determinants of the Tunisian deposit banks performance, Applied Financial Economics, 11, 317-9.

Rhoades, S. (1982) Welfare loss, redistribution effect and restriction of output due to monopoly, Journal of Monetary Economics, 9, 375-87.

Shen, C. (2005) Cost efficiency and banking performances in a partial universal banking system: application of the panel smooth threshold model, Applied Economics, 37, 993-1009.

Smirlock, M. (1985) Evidence of the (non) relationship between concentration and profitability in banking, Journal of Money, Credit and Banking, 17, 69-83.

Spellman, L. (1981) Commercial banks and the profit of saving and loans markets, Journal of Bank Research, 12, 32-9. 